\title{
Regulation ranges and patterns of adaptation to hyponatremia by cells of various organs and tissues of vertebrate animals
}

\author{
Martemyanov $\mathrm{VI}^{1}$, Poddubnaya $\mathrm{NY}^{2}$ \\ Papanin Institute for Biology of Inland Waters, Russian Academy of Sciences, 152742 Borok, \\ Yaroslavl oblast, Russia. martem@ibiw.yaroslavl.ru
}

\begin{abstract}
BACKGROUND: The effect of hyponatremia on the body is studied on model objects. The related question concerns the degree of compliance between manifestations of hyponatremia and protective mechanisms in humans and other species of vertebrates.

OBJECTIVES: To identify the regulation ranges and patterns of adaptation to hyponatremia by cells of various organs and tissues of vertebrate animals.

METHODS: To assess the regulation ranges and patterns of adaptation to hyponatremia, a comparative analysis has been applied to the data obtained from humans, mammals and freshwater fish.

RESULTS: The physiological content of sodium in the blood plasma in humans is regulated and maintained within a narrow value range which is similar to that occurring in a number of other vertebrate species. The counteraction to hyponatremia is performed by means of accelerating the transport of sodium, potassium, chloride and organic osmolytes from the cells into the internal environment.

CONCLUSIONS: The data regarding mammals are fragmented and reflect the manifestation of protective mechanisms taking place during the initial period of hyponatremia. The method tested on freshwater fish allows for studying patterned changes in inorganic ions and content of organic osmolytes in the internal environment and cells of various organs and tissues of the body from the start of developing hyponatremia till the completion of the recovery process in vivo (Fig. 2, Ref. 72). Text in PDF www.elis.sk.

KEY WORDS: humans, mammals, freshwater fish, blood plasma, tissue, normonatremia, hyponatremia, volume regulation of cells.
\end{abstract}

\section{Introduction}

Studies of humans $(1,2)$ and vertebrate animals $(3)$ demonstrate that the norm of sodium content in the internal environment is maintained within a certain narrow range (normonatremia), thus contributing to the optimal functioning of various body cells. Adverse factors reduce the level of sodium in blood plasma of humans (4-19), other mammals (20-31) and freshwater fish (32-37) below the norm.

Hyponatremia is accompanied by a decrease in the internal environment osmolality $(26,27,30,34)$, thus causing an osmotic difference between the extracellular and cellular fluids of the body. The osmotic gradient contributes to the movement of water from internal environment of the body into the cells of various

${ }^{1}$ Papanin Institute for Biology of Inland Waters, Russian Academy of Sciences, Borok, Yaroslavl oblast, Russia, and ${ }^{2}$ Cherepovets State University, Cherepovets, Vologda oblast, Russia

Address for correspondence: V.I. Martemyanov, Papanin Institute for Biology of Inland Waters, Russian Academy of Sciences, 152742 Borok, Yaroslavl oblast, Russia,.

Acknowledgements: This research was performed in the framework of the state assignment: Theme No. AAAA-A18-118012690101-2. We declare that we have no conflict of interest and no financial interest in publishing this manuscript. organs and tissues, thus causing their swelling and disruption of intracellular processes. On the other hand, cells of various organs and tissues of the body have adaptive mechanisms to cope with this situation.

Human tissue sampling is hazardous to health. Therefore, the effect of hyponatremia on the body and manifestation of protective mechanisms are investigated on model objects. The related question concerns the degree of compliance between manifestations of hyponatremia and protective mechanisms in humans and other species of vertebrates.

The purpose of the overview is to identify and compare the physiological regulated and hyponatremic ranges of the sodium content in the blood plasma of humans and other species of vertebrate animals. To assess the damaging effect and protective mechanisms of cell volume regulation in response to hyponatremia by various species of vertebrates.

\section{Methods}

To assess the regulated physiological ranges and those in response to hyponatremia, a comparative analysis of data on sodium content in blood plasma of humans, other mammals and freshwater fish has been performed. The data regarding the adaptation patterns to hyponatremia by the cells and tissues of various organs of mammals and freshwater fish have been summarized. 
Regulated physiological and hyponatremic ranges of sodium content in the blood plasma of humans and other vertebrates

\section{The humans}

Based on the summarized data, it has been demonstrated that the concentration of sodium in the blood plasma of healthy people is maintained within the range of $130-145 \mathrm{mmol} / \mathrm{L}$ (3). With regard to the norm, the concentration of sodium in the blood plasma of hospitalized patients decreased to $110 \mathrm{mmol} / \mathrm{L}(8), 108 \mathrm{mmol} / \mathrm{L}(6$, 9), $106 \mathrm{mmol} / \mathrm{L}(5), 104 \mathrm{mmol} / \mathrm{L}(7), 98 \mathrm{mmol} / \mathrm{L}(4), 96 \mathrm{mmol} / \mathrm{L}$ (19), or $93 \mathrm{mmol} / \mathrm{L}$ (13). The sodium content in the blood plasma of women decreased during menopause to $109 \mathrm{mmol} / \mathrm{L}$ (16). Various diuretics (thiazide groups) reduced the level of sodium in the blood serum of people to $108 \mathrm{mmol} / \mathrm{L}(10), 106 \mathrm{mmol} / \mathrm{L}(11,12$, 17), $99 \mathrm{mmol} / \mathrm{L} \mathrm{(14),} 98 \mathrm{mmol} / \mathrm{L}$ (18), or $96 \mathrm{mmol} / \mathrm{L} \mathrm{(15).} \mathrm{The}$ results demonstrate that with hyponatremia, the sodium content of human blood plasma can be reduced to the minimum value of $93 \mathrm{mmol} / \mathrm{L}$ (13). This value is probably the lowest limit for a human with severe form of hyponatremia.

\section{Mammals}

Some mammal species (rats, mice, rabbits, dogs) are used as test animals in medical research. Experimental procedures causing hyponatremia in rats reduced the blood plasma sodium levels from $135 \pm 1$ to $113 \pm 1 \mathrm{mmol} / \mathrm{L}$ (24), from $142 \pm 2$ to $109 \pm 3 \mathrm{mmol} / \mathrm{L}$ (22), from $142.1 \pm 0.3$ to $104.5 \pm 1.4 \mathrm{mmol} / \mathrm{L}(26)$, from 140 to 103 $\mathrm{mmol} / \mathrm{L}(27)$, from $139 \pm 1.5$ to $96 \pm 1 \mathrm{mmol} / \mathrm{L}(20)$, or from $132-145$ to $85 \mathrm{mmol} / \mathrm{L}(30)$. The data demonstrate that the sodium content in the blood plasma of the control group of rats is maintained within the range of $132-145 \mathrm{mmol} / \mathrm{L}$ (normonatremia), whereas under hyponatremia, it can be reduced to the limit value of $85 \mathrm{mmol} / \mathrm{L}$.

Experimental procedures causing hyponatremia reduced the concentration of sodium in the blood plasma from $142 \pm 1$ to $91 \pm 2$ $\mathrm{mmol} / \mathrm{L}$ in mice (29), and from $140 \pm 2$ to $118 \pm 3 \mathrm{mmol} / \mathrm{L}$ in rabbits (31). The comparison demonstrates that the values of sodium content in the blood plasma in the control groups in mice and rabbits (norm) and in those under hyponatremia are within the ranges of normonatremia and hyponatremia in humans and rats.

\section{Freshwater fish}

It has been demonstrated that the physiologic sodium concentration in the blood plasma of carps has been maintained within 129-135 mmol/L (3), while under hyponatremia it has decreased to $85.3 \pm 0.7 \mathrm{mmol} / \mathrm{L} \mathrm{(32)}$. In relation to the norm, the content of sodium in blood plasma in breams under stress has decreased from $134.5 \pm 0.9$ (range $126-147 ; \mathrm{n}=41$ ) to $95.6 \pm 3.4 \mathrm{mmol} / \mathrm{L}$ (range $73-$ $121 ; \mathrm{n}=23$ ), while that in roaches was reduced from $133.3 \pm 1$ (range $128-140 ; \mathrm{n}=16$ ) to $94.2 \pm 2.3 \mathrm{mmol} / \mathrm{L}$ (range $78-100 ; \mathrm{n}=15$ ) (36).

For comparison, the regulated physiological and hyponatremic ranges of sodium content in the internal environment of humans, other mammals and freshwater fish are presented in form of a diagram (Fig. 1). It demonstrates that the physiological ranges of sodium in the blood plasma of humans, rats, mice, rabbits, carps, breams and roaches, as well as those under hyponatremia, overlap. Interspecific differences relate to small differences at the lower

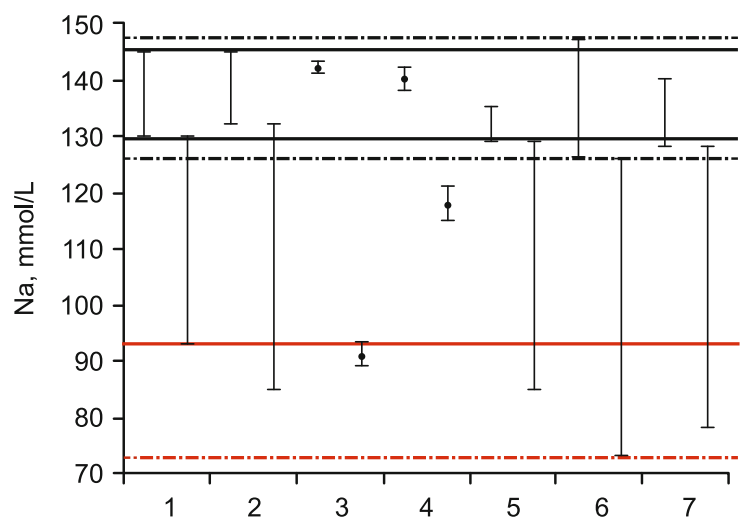

Fig. 1. Physiological regulated and hyponatremic ranges of sodium content in the blood plasma of humans (1), rats (2), mice (3), rabbits (4), carps (5), breams (6) and roaches (7). Black solid lines show the boundaries of normonatremia, while red solid line shows the limit of hyponatremia in the blood plasma of humans. Black dash-dotted lines show the boundaries of normonatremia, while the red dash-dotted line shows the limit of hyponatremia in the blood plasma of breams.

limit of normonatremia and to a greater degree at the lower limit of hyponatremia. In respect to the lower limit of normonatremia in humans (Fig. 1; lower black solid line), and in breams (black lower dash-dotted line), it is lower by $4 \mathrm{mmol} / \mathrm{L}$. The lower limit under hyponatremia in breams (Fig. 1; red dash-dotted line) is lower than that in humans (red solid line) by $20 \mathrm{mmol} / \mathrm{L}$.

Thus, the content of sodium in the blood plasma in humans, other mammals and freshwater fish is physiologically regulated within close narrow ranges. Interspecific differences are related to different magnitudes of manifested hyponatremia. This indicates interspecific differences in the resistance of the body cells to hyponatremia. The results demonstrate that the greatest resistance of body cells to hyponatremia is manifested by freshwater fish such as breams and roaches. In relation to the average physiologic values, the cells of various organs and tissues of breams can resist a decrease in sodium concentration in the internal environment by $46 \%$, whereas those of humans only by $32 \%$.

\section{Damaging effect of hyponatremia on the cells of various body tissues and organs of vertebrate animals}

The decrease in the sodium level in the blood plasma under adverse conditions is accompanied by a drop in the osmolality of the body internal environment. Under hyponatremia, osmotic plasma/serum concentrations in rats decreased from $302 \pm 2$ to $237 \pm 8 \mathrm{mOsmol} / \mathrm{kg}$ (22), from $297 \pm 6$ to $232 \pm 6 \mathrm{mOsmol} / \mathrm{kg}$ (23), or from $288 \pm 1$ to $226 \pm 1 \mathrm{mOsmol} / \mathrm{kg}$ (26). In breams, it decreased from $275 \pm 3$ to $243 \pm 6 \mathrm{mOsmol} / \mathrm{kg}$ of water (34).

This results in an osmotic drop between internal environment and intracellular fluid of the body in various organs and tissues, which promotes movement of water into the cells and causes them to swell. It is shown that in the initial period of acute stress caused by capture and transportation, there is a sharp decrease in the concentration of sodium in the blood plasma of freshwater fish 


\section{8-224}

(34-37), which is accompanied by an increase in water content in the body of roaches from $72.1 \pm 0.35$ to $75.6 \pm 0.59 \%$ (38), and in muscle tissue of breams from $78.1 \pm 0.6$ to $80.1 \pm 0.3 \%$ (34) or from $79.6 \pm 0.2$ to $81.8 \pm 0.6 \%$ (37). Under hyponatremia, the water content in the rabbit brain increased by $7-17 \%$ (8), or $11 \%(31)$, and in the rat brain by $12 \%(21,24)$.

Brain swelling is the most damaging event in the body. The skull prevents the expansion of this tissue. Therefore, brain edema under hyponatremia is accompanied by an increase in intracranial pressure with a number of concomitant negative consequences, including high mortality $(9,39,40)$.

\section{Protective mechanisms confronting the damaging effect of hyponatremia}

In response to cell swelling caused by hyponatremia/hypoosmolality, the protective functions of structures and systems associated with the transfer of inorganic ions and organic osmolites from intracellular fluid through cell membranes to the internal environment of the body intensify. Initially, this process counteracts the development of a more severe hyponatremia and hypoosmolality, and then, after a certain period of time, it restores the volume of the body's cells to its original value.

The mechanisms of cell volume regulation in response to hyponatremia/hypoosmolality are studied mainly in vitro experiments. In vitro experiments allow sampling during the experiment with fractional intervals ( $1-10$ minutes) for $2-3$ hours. With this regard, the manifestation of initial stages of damaging and protective processes in response to the decrease in concentration of sodium and chloride in physiological solution have been studied in experiments in vitro. The data regarding the volume regulation by various cell types obtained in vitro are summarized in a number of reviews (41-50).

The data obtained in experiments in vivo regarding the protective reactions counteracting the increase in cellular volume and its msubsequent restorations are fragmentary due to objective reasons. For a large group of animals, it is difficult to simultaneously ensure hyponatremia with a similar degree of development and to select samples for analysis from the general population at certain intervals. Therefore, the results obtained in experiments in vivo are related to the control group and 1-3 samples taken from animals within one or another time period after the hyponatremia starts to develop.

Protective mechanisms counteracting hyponatremia in vivo, in the brain of humans and other mammals

Brain swelling is the most dangerous damage to the body. Due to this, the main attention of researchers is aimed at studying the mechanisms of brain cells' volume regulation. The methods that would allow to determine the content of inorganic ions in vivo without removing samples from the body are not available. Therefore, the participation of inorganic ions in regulation of human brain cells' volume has not been studied.

Proton magnetic resonance spectroscopy (MRS) is a technology that allows for conducting quantitative assessments of organic substances in the brain in vivo (51). This method is used in studies of humans. It was demonstrated that in comparison to healthy people, the gray brain substance of the patients with chronic hyponatremia contains lowered levels of organic osmolites, namely myo-inositol by $49 \%$, choline-containing compounds by $36 \%$, creatine/phosphocreatine by $19 \%$, and $\mathrm{N}$-acetylaspartate by $11 \%$ (52). A patient with severe hyponatremia had almost undetectable concentrations of myo-inositol and glutamine/glutamate in the brain (53). The patients with hyponatremia showed a significant reduction in myo-inositol, creatine, and choline-containing compounds concentration in the brain compared to the patients without hyponatremia $(54,55)$.

The main test animals in medical research are rats. Through various procedures, hyponatremia of different durations is induced in these animals. The data obtained from blood plasma and brain samples taken from selected rats in the state of hyponatremia are compared to the results of the control group.

The main inorganic electrolytes involved in volume regulation of cells are ions of sodium, potassium and chlorine. It has been demonstrated that hyponatremia with duration of 7-74 hours was accompanied by a decrease in sodium concentration in the rat brain by $22-28 \%$, and potassium by $13-16 \%$ (21). In response to hyponatremia, the content of sodium, potassium, and chlorine in the rat brain sharply decreased after 3 hours, respectively by $34 \%, 23 \%$, and $40 \%$ (28). When compared with controls, hyponatremic rats had a significantly reduced brain content of sodium, potassium, chloride, glutamate, myo-inositol, N-acetylaspartate, aspartate, creatine, taurine, gamma-aminobutyric acid, and phosphoethanolamine (20). Under hyponatremia, the total concentration of organic osmolytes decreased in different parts of the brain of rats by $45-55 \%$ (23).

Thus, the data obtained from humans and rats are limited and fragmented and reflect the manifestation of protective mechanisms in a certain period of hyponatremia. It is important to know the manifestation of the damaging processes and protective mechanisms in the course of time, i.e. from the appearance of hyponatremia to the completion of recovery. In clinical and laboratory conditions, the conducting of such a mammal study is not possible due to several reasons. This type of experiment requires a large quantity of animals. This requires large-sized premises for reproduction and subsequent keeping of animals. Additionally, the existing methods technically do not allow for a large number of animals to develop hyponatremia simultaneously, so that later on, the selections for sampling and subsequent analysis can be taken from the general population at certain time periods. The methods of inducing hyponatremia include injecting animals with certain substances, including distilled water. It is not possible to inject a large number of animals at the same time. The method tested on freshwater fish allows for studying the manifestation of the damaging processes and protective mechanisms from the start of hyponatremia development to the completion of adaptation.

\section{Protective mechanisms opposing hyponatremia in vivo in eryth- rocytes and muscle cells of freshwater fish}

The capture and transportation of freshwater fish causes stress, which is accompanied by severe hyponatremia (35-37). It is possible to catch simultaneously a large number of certain fish species by seine, while triggering their stress reaction at the same time. Through 


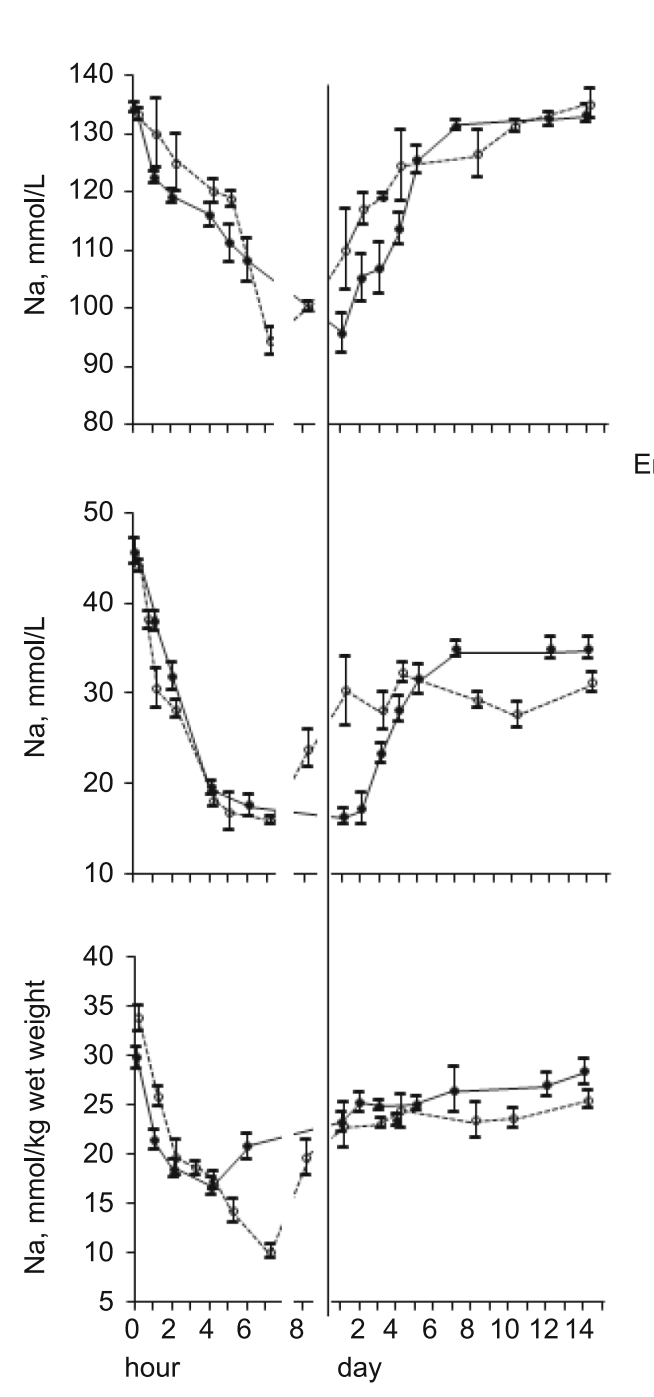

Plasma

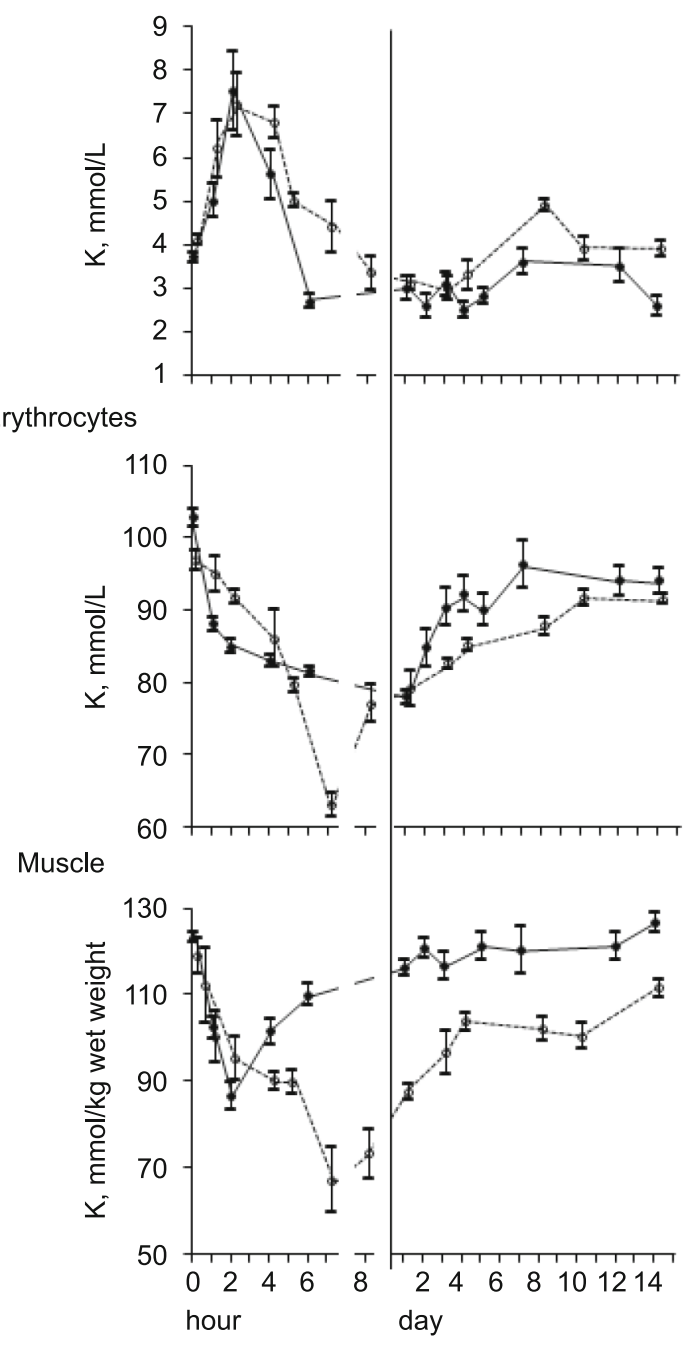

Fig. 2. Dynamics of sodium and potassium ions content in plasma, erythrocytes, and muscles of breams $(\bullet)$ and roaches $(\circ)$ in response to their capture, 3-hour-long transportation and acclimation in the cage.

selecting samples from the total number of caught fish, it is possible to trace the manifestation of damage and protective mechanisms from the start of the influence to the completion of recovery processes.

Figure 2 shows the results of two experiments (36). The breams (107 specimens) were caught by one 15-min-long trawling; the roaches (119 specimens) were caught by one 15-min-long seine netting. The samples were taken at each time interval from six fish of each species immediately after the capture, then from two groups of fish during transportation, and then at specified time intervals during acclimation of fish in cages.

The results demonstrate that the concentration of sodium in the blood plasma of roaches and breams at the initial period of stress decreased significantly compared to the initial values. This is caused by the intensified output of sodium from the fish blood into external environment. It has also been observed that the leakage of chloride ions from the body of freshwater fish increases in the initial period of stress and leads to a significant decrease in its level in blood plasma $(56,57)$.
The decrease in the content of sodium and chloride in the blood plasma of freshwater fish under stress is accompanied by a decrease in osmolality in the internal environment of the organism $(33,34)$. It results in the development of osmotic pressure difference between cellular and extracellular liquids of the organism, thus supporting the movement of water into the cells and causing their swelling.

For counteracting the negative processes caused by hyponatremia/ hypoosmolality, the defensive reactions of the organism related to the extraction of ions from intracellular liquid intensify. It has been observed that the concentration of sodium and potassium in erythrocytes and muscles of roaches and breams significantly decrease at the initial period of acute stress (Fig. 2). The levels of sodium, potassium and chloride decreased in rat brain in response to hyponatremia $(20,21,28)$. A limited quantity of data obtained from in vivo experiments indicates that the body cells of mammals (rats) and freshwater fish (breams and roaches) respond to hyponatremia in a similar manner due to the loss of 
sodium, potassium and chloride from the intracellular fluid into the internal environment.

The output of ions from intracellular fluid into the extracellular environment counteracts the development of heavier hyponatremia and hypoosmolality. However, despite the significant loss of these ions from cells at the initial stage of acute stress, the complete compensation for hyponatremia (Fig. 2) and hypochloremia (56, $57)$ is not achieved, which then causes hypoosmolality $(33,34)$.

Synchronous decrease in sodium and potassium concentration in erythrocytes and muscles of roaches and breams at the initial period of hyponatremia indicates that the possible mechanism of their excretion from cells may be connected to the activation of $\mathrm{Na}^{+}-\mathrm{K}^{+}-2 \mathrm{Cl}^{-}$cotransporter. This carrier is found on the membranes of various types of cells, including those of epithelium, endothelium, nerves, muscles, fibroblasts, and red blood cells (58-62). The participation of the $\mathrm{Na}^{+-} \mathrm{K}^{+-} 2 \mathrm{Cl}^{-}$cotransporter in the regulation of cellular volume has been studied in vitro.

It has been demonstrated that the activity of the $\mathrm{Na}^{+}-\mathrm{K}^{+}-2 \mathrm{Cl}^{-}$cotransporter is enhanced in response to hypernatremic/hyperosmotic solutions, which accelerates the entry of sodium, potassium, and chloride into cells, whereas under the action of hyponatremic/hypoosmotic solutions, the $\mathrm{K}^{+}-\mathrm{Cl}^{-}$cotransporter increases the effluxes of potassium and chloride from the cells $(49,63-66)$. After osmotic swelling, troutred blood cells showed a net loss of potassium, chloride and amino acids, while the sodium content in the cells increased (67).

Thus, in the experiments in vivo, the counteraction to swelling of body cells during hyponatremia is carried out by increasing the loss of sodium, potassium and chloride from the cells, thus indicating a possible involvement of the $\mathrm{Na}^{+}-\mathrm{K}^{+}-2 \mathrm{Cl}^{-}$cotransporter in this process. In the experiments in vitro, the counteraction to cellular swelling in response to a sharp decrease in sodium and chloride content in the solution is performed by increasing the effluxes of potassium and chloride from the cells, namely by increasing the activity of the $\mathrm{K}^{+}-\mathrm{Cl}^{-}$cotransporter.

The comparative analysis demonstrates that in response to hyponatremia in vivo as well as to the decrease in concentration of sodium and chloride in solution in vitro experiments, the patterns of cellular volume regulation differ. Therefore, for adequate understanding of the processes occurring during the adaptation of various types of cells to the decrease in osmotic concentration of extracellular fluid, it is required to obtain the data in vivo. The method tested on freshwater fish makes it possible to study in vivo the patterns of changes in the content of inorganic ions and organic osmolites in the internal environment and cells of various organs and tissues of the body from the beginning of hyponatremia development to the completion of the recovery process.

\section{Acute and chronic hyponatremia}

Scientific literature applies two terms in relation to hyponatremia, namely acute and chronic hyponatremia. However, no clear criteria are proposed that would allow for an objective assessment of these forms of hyponatremia. In practice, the type of hyponatremia is assessed conditionally, based on its duration. At the same time, the proposed periods differ in duration, both for acute and chronic hyponatremia. Such assessment is subjective and does not essentially reflect qualitative differences between the two forms of hyponatremia.

\section{Acute form of hyponatremia}

The criterion of acute hyponatremia is a change in concentration of sodium in the internal environment of the body during the entire period of its manifestation (Fig. 2). The entire period is divided into two intervals. In the initial period of acute hyponatremia, the concentration of sodium in blood plasma decreases over a certain period of time from normal value to the minimum level, while reflecting the predominance of damaging processes over the protective functions of the body. Excessive impacts can cause a decrease in concentration of sodium in the internal environment to the values incompatible with vital functions of cells in various organs and tissues, thus causing death of the body. In clinical practice, in order to reduce mortality of patients, acute hyponatremia is corrected by means of applying hypertonic solutions.

The second period of acute hyponatremia is characterized by an increase in sodium content in the internal environment of the body to the normal level, while reflecting the predominance of protective functions over the damaging processes. The acute form of hyponatremia is caused by short-term adverse effects.

\section{Chronic form of hyponatremia}

The criterion of chronic hyponatremia is a long-term maintenance of sodium content in the internal environment of the body at a stable lowered level. Chronic hyponatremia occurs in response to the durable impact of external and internal adverse factors (chronic diseases). Patients with cirrhosis (68-72) and fish (breams) inhabiting water with increased level of anthropogenic pollution (37) demonstrate chronic hyponatremia. The attempts to correct chronic hyponatremia cannot be successful without eliminating its causes. Chronic hyponatremia, even after its correction, will occur again, and continue until the cause is eliminated. Therefore, it is foremostly necessary to eliminate the causes of chronic hyponatremia. After eliminating the cause, the body will restore the physiologic sodium content in the internal environment by itself.

\section{Conclusion}

The physiological and hyponatremic ranges of sodium content in the blood plasma of humans, rats, mice, rabbits, carps, breams and roaches overlap. The patterns of adaptation to hyponatremia in brain cells of rats, and in muscle and erythrocytes of breams and roaches are carried out in a similar manner, namely by means of losing sodium, potassium and chlorine from body cells, possibly through an increased activity of the $\mathrm{Na}^{+}-\mathrm{K}^{+}-2 \mathrm{Cl}^{-}$cotransporter. The body cells partially adapt to hyponatremia by means of losing organic osmolytes. The patterns of cell volume regulation in response to hyponatremia in vivo differ from those to the decrease in concentration of sodium and chloride in solution in vitro experiments. In the experiments in vitro, the counteraction to cell swelling in response to a sharp decrease in sodium and chloride contents in solution is carried out by means of increasing the ef- 
fluxes of potassium and chloride from cells through increasing the activity of $\mathrm{K}^{+}-\mathrm{Cl}^{-}$cotransporter. For adequate understanding of the processes occurring during the adaptation of different cell types to hyponatremia, the data obtained in vivo are required. The data about humans and rats obtained in vivo are limited and fragmented, and reflect the manifestation of protective mechanisms in one or another initial period of hyponatremia. It is important to understand the manifestation of the damaging processes and protective mechanisms in time from the start of hyponatremia development to the completion of recovery. Under clinical and laboratory conditions, the conducting of such study on mammals is not possible due to several reasons. The catching and transporting the freshwater fish causes acute hyponatremia, and subsequent acclimation of animals in cages or swimming pools leads to full recovery of all indicators of the body. This simple and convenient technique allows studying the patterns of changes in the content of inorganic ions and organic osmolytes in the internal environment and cells of various organs and tissues of the body in vivo from the start of hyponatremia development to the completion of the recovery process. Under laboratory conditions, it is convenient to create and study chronic hyponatremia of fish by introducing certain substances into the water, thus causing a long-term adverse impact on the body. The criterion of acute hyponatremia is a change in concentration of sodium in the internal environment of the body during the entire period of its manifestation. The criterion of chronic hyponatremia is a long-term maintenance of sodium content in the internal environment of the body at a stable lowered level.

\section{References}

1. Mendes RS, Soares M, Valente $\mathbf{C}$ et al. Predialysis hypernatremia is a prognostic marker in acute kidney injury in need of renal replacement therapy. J Crit Care 2015; 30: 982-987.

2. Han SS, Bae E, Kim DK et al. Dysnatremia, its correction, and mortality in patients undergoing continuous renal replacement therapy: a prospective observational study. BMC Nephrology 2016; https://doi.org/10.1186/ s12882-015-0215-1.

3. Martemyanov VI, Poddubnaya NY. Volume regulation of muscle cells in the carp Cyprinus carpio in response to hypernatremia. Bratisl Med J 2019; 120: 52-57.

4. Berl T. Treating hyponatremia: damned if we do and damned if we do not. Kidney Int 1990; 37: 1006-1018.

5. Adrogue HJ, Madias NE. Hyponatremia. N Engl J Med 2000; 342: 1581-1589.

6. Ayus JC, Krothapalli RK, Arieff AI. Treatment of symptomatic hyponatremia and its relation to brain damage. A prospective study. $\mathrm{N}$ Engl $\mathrm{J}$ Med 1987; 317: 1190-1195.

7. Achinger SG, Moritz ML, Ayus JC. Dysnatremias: why are patients still dying? South Med J 2006; 99: 353-362.

8. Arieff AI, Llach F, Massry SG. Neurological manifestations and morbidity of hyponatremia: correlation with brain water and electrolytes. Medicine (Baltimore) 1976; 55: 121-129.

9. Arieff AI. Hyponatremia, convulsions, respiratory arrest, and permanent brain damage after elective surgery in healthy women. N Engl J Med 1986; 314: 1529-1535.
10. Ashouri OS. Severe diuretic-induced hyponatremia in the elderly. A series of eight patients. Arch Intern Med 1986; 146: 1355-1357.

11. Booker JA. Severe symptomatic hyponatremia in elderly outpatients: the role of thiazide therapy and stress. J Am Geriatr Soc 1984; 32: 108-113.

12. Chow KM, Kwan BC, Szeto CC. Clinical studies of thiazide-induced hyponatremia. J Natl Med Assoc 2004; 96: 1305-1308.

13. Brunner JE, Redmond JM, Haggar AM et al. Central pontine myelinolysis and pontine lesions after rapid correction of hyponatremia: a prospective magnetic resonance imaging study. Ann Neurol 1990; 27: 61-66.

14. Ashraf N, Locksley R, Arieff A. Thiazide-induced hyponatremia associated with death or neurologic damage. Am J Med 1981; 70:1163-1168.

15. Sonnenblick M, Friedlander Y, Rosin AJ. Diuretic-induced severe hyponatremia. Chest 1993; 103: 601-606.

16. Ayus JC, Arieff AI. Chronic hyponatremic encephalopathy in postmenopausal women: association of therapies with morbidity and mortality. JAMA 1999; 281: 2299-2304.

17. Hwang KS, Kim G-H. Thiazide-induced hyponatremia. Electrolytes Blood Press 2010; 8: 51-57.

18. Chow KM, Szeto CC, Wong TY-H et al. Risk factors for thiazideinduced hyponatraemia. QJM: Inter J Med 2003; 96: 911-917.

19. Tomlinson BE, Pierides AM, Bradley WG. Central pontine myelinolysis: two cases with associated electrolyte disturbance. QJM: Inter J Med 1976; 45: 373-386.

20. Sterns RH, Baer J, Ebersol S et al. Organic osmolytes in acute hyponatremia. Am J Phisiol 1993; 264: F833-F836.

21. Sterns RH, Thomas DJ, Herndon RM. Brain dehydration and neurologic deterioration after rapid correction of hyponatremia. Kidney Int 1989; 35: 69-75.

22. Lien YH, Shapiro JI, Chan L. Study of brain electrolytes and organic osmolytes during correction of chronic hyponatremia: implications for the pathogenesis of central pontine myelinolysis. J Clin Invest 1991; 88: 303-309.

23. Lien YH. Role of organic osmolytes in myelinolysis a topographic study in rats after rapid correction of hyponatremia. J Clin Invest 1995; 95:1579-1586.

24. Silver SM, Schroeder BM, Bernstein P, Sterns RH. Brain adaptation to acute hyponatremia in young rats. Am J Physiol Regul Integr Comp Physiol 1999; 276: R1595-R1599.

25. Soupart A, Silver S, Schroöeder B et al. Rapid (24-Hour) reaccumulation of brain organic osmolytes (particularly myo-Inositol) in azotemic rats after correction of chronic hyponatremia. J Am Soc Nephrol 2002; 13: 1433-1441.

26. Verbalis JG, Drutarosky MD. Adaptation to chronic hypoosmolality in rats. Kidney Inter 1988; 34: 351-360.

27. Melton JE, Nattie EE. Brain and CSF water and ions during dilutional and isosmotic hyponatremia in the rat. Am J Physiol 1983; 244: R724-R732.

28. Melton JE, Patlak CS, Pettigrew KD, Cserr HF. Volume regulatory loss of $\mathrm{Na}, \mathrm{Cl}$, and $\mathrm{K}$ from rat brain during acute hyponatremia. Am J Physiol 1987; 252: F661-F669.

29. Thurston JH, Hauhart RE, Nelson JS. Adaptive decreases in amino acids (taurine in particular), creatine, and electrolytes prevent cerebral edema in chronically hyponatremic mice: rapid correction (experimental model of central pontine myelinolysis) causes dehydration and shrinkage of brain. Metabolic Brain Disease 1987; 2: 223-241.

30. Holliday MA, Kalayci MN, Harrah J. Factors that limit brain volume changes in response to acute and sustained hyper- and hyponatremia. J Clin Invest 1968; 47: 1916-1928. 
31. Ayus JC, Armstrong D, Arieff AI. Hyponatremia with hypoxia: Effects on brain adaptation, perfusion, and histology in rodents. Kidney Inter 2006; 69: 1319-1325.

32. Fida Sh, Qadri MYa, Siddiqi M. Influence of environmental conditions on the ovarian cycle and serum chemistry of Cyprinus carpio in the Dal lake, Kashmir (India). Fresh Biol 1988; 20: 61-67.

33. Davis KB, Parker NC. Physiological stress in striped bass: effect of acclimation temperature. Aquaculture 1990; 91: 349-358.

34. Natochin YuV, Shakhmatova EI, Lavrova EA et al. Volume regulation of cells of certain organs and tissues of freshwater and anadromous fish upon changes in the osmolality and ionic composition of serum. Zh Evol Biokhim Fiziol 1991; 27: 159-166.

35. Martemyanov V.I. Patterns of changes in sodium content in plasma and erythrocytes of freshwater fish at stress. J Ichthyol 2013; 53: 220-224.

36. Martemyanov VI. Dynamics of sodium and potassium in plasma, erythrocytes, and muscles of freshwater species under the effect of long-term combined stress. Inland Water Biology 2014; 7: 389-393.

37. Martemyanov VI. Assessment of acute and chronic stress in freshwater fish in index of water-salt metabolism. Uspekhi sovremennoy biologii 2014; 134: 265-273.

38. Martemyanov VI. Dynamics of the content of various fractions of water in the organism of roach Rutilus rutilus L. in response to catching, transportation, and further acclimation to laboratory conditions. Inland Water Biology 2015; 8: 402-405.

39. Arieff AI. Influence of hypoxia and sex on hyponatremic encephalopathy. Am J Med 2006; 119: 59-64.

40. Garigan TP, Ristedt DE. Death from hyponatremia as a result of acute water intoxication in an army basic trainee. Mil Med 1999; 164: 234-238.

41. Schmidt-Nielsen B. Comparative physiology of cellular ion and volume regulation. J Exp Zool 1975; 194: 207-219.

42. Grantham J, Linshaw M. The effect of hyponatremia on the regulation of intracellular volume and solute composition. Circ Res 1984; 54: 483-491.

43. Chamberlin ME, Strange K. Anisosmotic cell volume regulation: a comparative view. Am J Physiol 1989; 257: C159-C173.

44. Okada Y, Maeno E, Shimizu T et al. Receptor-mediated control of regulatory volume decrease (RVD) and apoptotic volume decrease (AVD). J Physiol 2001; 532: 3-16.

45. Ordaz B, Tuz K, Ochoa LD et al. Osmolytes and mechanisms involved in regulatory volume decrease under conditions of sudden or gradual osmolarity decrease. Neurochem Res 2004; 29: 65-72.

46. Pasantes-Morales H, Lezama RA, Ramos-Mandujano G. Tyrosine kinases and osmolyte fluxes during hyposmotic swelling. Acta Physiol 2006; 187: 93-102.

47. Pasantes-Morales H. Taurine homeostasis and volume control. Adv Neurobiol 2017; 16: 33-53.

48. Hoffmann EK, Simonsen LO, Lambert IH. Cell volume regulation: intracellular transmission. Adv Comp Env Physiol 1993; 14: 187-248.

49. Hoffmann EK, Lambert IH, Pedersen SF. Physiology of cell volume regulation in vertebrates. Physiol Rev 2009; 89; 193-277.

50. Hoffmann EK. Ion channels involved in cell volume regulation: effects on migration, proliferation, and programmed cell death in non adherent EAT cells and adherent ELA cells. Cell Physiol Biochem 2011; 28: 1061-1078.

51. Novotny E, Ashwal S, Shevell M. Proton magnetic resonance spectroscopy: an emerging technology in pediatric neurology research. Ped Res 1998; 44: 1-10
52. Videen JS, Michaelis T, Pinto P, Ross BD. Human cerebral osmolytes during chronic hyponatremia. A proton magnetic resonance spectroscopy study. J Clin Invest 1995; 95: 788-793.

53. Häussinger D, Laubenberger J, Vom Dahl S et al. Proton magnetic resonance spectroscopy studies on human brain in hypo-osmolarity and hepatic encephalopathy. Gastroenterology 1994; 107: 1475-1480.

54. Restuccia T, Gomez-Anson B, Guevara M et al. Effects of dilutional hyponatremia on brain organic osmolytes and water content in patients with cirrhosis. Hepatology 2004; 39: 1613-1622.

55. Guevara M, Baccaro ME, Torre A et al. Hyponatremia is a risk factor of hepatic encephalopathy in patients with cirrhosis: a prospective study with time-dependent analysis. Am J Gastroenterol 2009; 104: 1382-1389.

56. Barton BA, Haukenes AH, Parsons BG, Reed JR. Plasma cortisol and chloride stress responses in juvenile alleyes during capture, transport, and stocking procedures. N Amer J Aquaculture 2003; 65: 210-219.

57. Postlethwaite EK, McDonald DG. Mechanisms of $\mathrm{Na}^{+}$and $\mathrm{Cl}^{-}$regulation in freshwater adapted rainbow trout (Oncorhynchus mykiss) during exercise and stress. J Exp Biol 1995; 198: 295-304.

58. Haas M. The Na-K-Cl cotransporters. Am J Physiol 1994; 267: C869C885.

59. Haas M, Forbush B. The Na-K-Cl cotransporters. J Bioenerg Biomembr 1998; 30: 161-172.

60. Haas M, Forbush B. The Na-K-Cl cotransporter of secretory epithelia. Annu Rev Physiol 2000; 62: 515-534.

61. Russell JM. Sodium-potassium-chloride cotransport. Physiol Rev 2000; 80: 211-276.

62. Zheng S, Krump NA, McKenna MM et al. Regulation of erythrocyte $\mathrm{Na}^{+} / \mathrm{K}^{+} / 2 \mathrm{Cl}$ - cotransport by an oxygen-switched kinase cascade. J Biol Chem 2019; 294: 2519-2528.

63. Lang F, Busch GL, VolkI H. The diversity of volume regulatory mechanisms. Cell Physiol Biochem 1998; 8: 1-45.

64. Lytle C, McManus T. Coordinate modulation of $\mathrm{Na}-\mathrm{K}-2 \mathrm{Cl}$ cotransport and $\mathrm{K}-\mathrm{Cl}$ cotransport by cell volume and chloride. Am J Physiol Cell Physiol 2002; 283: C1422-C1431

65. Di Ciano-Oliveira C, Sirokmány G, Szászi K et al. Hyperosmotic stress activates Rho: differential involvement in Rho kinase-dependent MLC phosphorylation and NKCC activation. Am J Physiol Cell Physiol 2003; 285: C555-C566.

66. Strange K. Cellular volume homeostasis. Adv Physiol Educ 2004; 28 : $155-159$.

67. Garcia-Romeu F, Cossins AR, Motais R. Cell volume regulation by trout erythrocytes: characteristics of the transport systems activated by hypotonic swelling. J Physiol 1991; 440: 547-567.

68. Ginés P, Berl T, Bernardi M et al. Hyponatremia in cirrhosis: from pathogenesis to treatment. Hepatology 1998; 28: 851-864.

69. Ginès P, Guevara M. Hyponatremia in cirrhosis: pathogenesis, clinical significance, and management. Hepatology 2008; 48: 1002-1010.

70. Gerbes AL, Gülberg V, Ginès $P$ et al. Therapy of hyponatremia in cirrhosis with a vasopressin receptor antagonist: a randomized double-blind multicenter trial. Gastroenterology 2003; 124: 933-939.

71. Sigal SH. Hyponatremia in cirrhosis. J Hosp Med 2012; 7: S14-S17.

72. Attar B. Approach to hyponatremia in cirrhosis. Clin Liver Dis (Hoboken) 2019 ; 13: 98-101.

Received October 8, 2019. Accepted November 27, 2019. 